\title{
Influence of Structural Shape on Earth Pressure for High-Filled Cut-and-Cover Tunnel with and without Load Reduction Based on Discrete Element Method
}

\author{
Sheng Li $\mathbb{D},,^{1,2}$ Liangliang Zhao, ${ }^{1,2}$ I-Hsuan Ho $\mathbb{D}^{3}{ }^{3}$ Guixia Ning, ${ }^{1,2}$ Bentian Yu, ${ }^{1,2}$ \\ and Changdan Wang ${ }^{4}$ \\ ${ }^{1}$ College of Civil Engineering, Lanzhou Jiaotong University, Lanzhou 730070, Gansu, China \\ ${ }^{2}$ National and Provincial Joint Engineering Laboratory of Road \& Bridge Disaster Prevention and Control, \\ Lanzhou Jiaotong University, Lanzhou 730070, Gansu, China \\ ${ }^{3}$ Harold Hamm School of Geology and Geological Engineering, University of North Dakota, 81 Cornell St. Stop. 8358, \\ Grand Forks 58202, North Dakota, USA \\ ${ }^{4}$ Department of Urban Rail Transit and Railway Engineering, College of Transportation Engineering, Tongji University, \\ Shanghai 201804, China
}

Correspondence should be addressed to Sheng Li; lis@mail.lzjtu.cn and I-Hsuan Ho; ihsuan.ho@und.edu

Received 5 July 2020; Revised 14 September 2020; Accepted 18 September 2020; Published 8 October 2020

Academic Editor: Mehmet Serkan Kirgiz

Copyright $\odot 2020$ Sheng Li et al. This is an open access article distributed under the Creative Commons Attribution License, which permits unrestricted use, distribution, and reproduction in any medium, provided the original work is properly cited.

In the construction of the Loess Plateau in China, high-filled cut-and-cover tunnels (HFCCTs) had solved the problem of the shortage of land resources. However, this type of structure has a large amount of backfill soil, which leads to the problems of ultrahigh earth pressure and safety of the cut-and-cover tunnels (CCTs) lining structure. Previous studies have focused on the load reduction of various flexible materials, ignoring the influence produced by the shape of the CCT structure on the load reduction. Therefore, via a discrete element software, we investigated the changes of vertical earth pressure (VEP), vertical displacement, lateral earth pressure (LEP), and load transfer mechanisms around a HFCCT with consideration to two cases: (1) different shape of CCT structure; (2) the coupling of load reduction using expanded polystyrene (EPS) and the modified shape of the CCT lining structure. The results obtained by the discrete element method (DEM) revealed that an appropriate structural shape influenced the reduction of the VEP above the CCT and that the coupled effects of the load reduction using the EPS and shape modifications of the CCT lining structure could significantly reduce the VEP above the CCT, which enhanced the safety of the CCT. Meanwhile, the optimal values for the shapes of CCTs are derived.

\section{Introduction}

In the Loess Plateau of Northwest China, deep valleys pose challenges in the construction of high-speed railways and highways, and a certain amount of backfill soil is required. Thus, high-filled cut-and-cover tunnels (HFCCTs) are employed. However, such high fill causes an overload of earth pressure above the tunnel, which can adversely affect the safety of the tunnel and cause longitudinal cracking. Therefore, to ensure the safety of the tunnel's lining structure, reasonable measures are required.
In terms of load reduction for culverts, Marston [1] confirmed that the vertical load on the culverts can be reduced by laying lightweight materials. Subsequently, by laying a flexible material above the structure and investigating the structure-soil interaction effect, it was concluded that a good load reduction effect can be achieved by laying a flexible material plate above the structure [2-7]. Similarly, the effects of different load reduction measures have been analyzed through laboratory tests [8] and finite element simulations [9]. To date, a large number of compressible materials, such as leaves [10], baled straw [11], sawdust or 
woodchips [12], expanded polystyrene (EPS) [13-15], and geogrid [16-18] have been investigated.

In studies on the shape of the culvert section, the following cross section shapes have mainly been investigated: box culvert [19-27], arched culvert [28], pipe culvert [29-36], and cover culvert [37]. Additionally, relevant research has been conducted on the changes in the culvert diameter [38] and the degree of arch shape [39].

For HFCCTs, because the earth pressure above a cutand-cover tunnel (CCT) is significant [40], some type of load reduction is needed. Similar load reduction measures, employing geogrid and EPS, geogrid and concrete wedges, and EPS and relatively low-compacted soil, have been shown to be applicable to HFCCTs [41, 42].

Currently, researchers are focusing mainly on load reduction and the structural shape of culverts. For HFCCTs, several studies have mainly focused on load reduction. Few studies have been conducted on changes in earth pressure when the shape of the CCT structure is different [43]. Thus, in this paper, the particle flow code two-dimensional (PFC2D) software was used to analyze the distribution of vertical earth pressure (VEP) above the CCT, vertical displacement above the CCT, and distribution of lateral earth pressure (LEP) on the side of the CCT with different structural shape, regardless of whether load reduction above the CCT was used or not. Moreover, the microlevels of porosity, coordination number, and contact force chain were investigated. The obtained results and conclusions are presented in this paper.

\section{Numerical Simulation}

A numerical simulation was conducted using PFC2D, which is computer code based on the discrete element method (DEM) [44], to investigate the variation of earth pressure and displacement around the CCT with or without EPS when the shape of the CCT structure is different.

2.1. Design of Scheme. According to the research object, two schemes were designed as presented in Table 1 . Case S1 has a backfill height of $h=1.2 \mathrm{~m}$, CCT width of $S=0.2 \mathrm{~m}$, foundation width of $B=0.6 \mathrm{~m}$, the slope angle of $\beta=70^{\circ}$, and the shape of CCT structure was changed by the ratios of the curved arch height to the CCT span (H/S ratio). In the study, $H / S=0.4-0.9$ was considered. Compared with case S1, the backfill above the CCT was replaced with EPS for case S2, which had a thickness of $15 \mathrm{~cm}$ and a width of $30 \mathrm{~cm}(1.5 \mathrm{~S})$.

2.2. Model Establishment. In the modeling process using PFC2D, this study used an improved multilayer compaction method (IMCM) to generate the initial model [45]. The PFC2D model for case S2 with a height-span ratio of 0.5 is shown in Figure 1. This numerical model was to simulate the physical model test in the laboratory. The scale ratio between the experimental model and the numerical model is 3.0. In the model, the backfill was divided into six layers and had relative compaction of $R=85 \%$ and porosity of $n=0.15$. The total height of the model was $1.3 \mathrm{~m}$, which included a backfill height of $1.2 \mathrm{~m}$ and a blank height of $0.1 \mathrm{~m}$. The curved arch height $(H)$ changed with the change of the $H / S$ ratio. When the $H / S$ ratio was 0.4 to 0.9 , the CCT height was $0.18 \mathrm{~m}$, $0.20 \mathrm{~m}, 0.22 \mathrm{~m}, 0.24 \mathrm{~m}, 0.26 \mathrm{~m}$, and $0.28 \mathrm{~m}$, respectively (see Figure 2). When modeling the EPS, a $0.15 \mathrm{~m}$ high and $0.30 \mathrm{~m}$ long area was used to simulate EPS above the CCT. Next, the soil particles in this area were deleted, the EPS particles ranging from $6 \mathrm{~mm}$ to $10 \mathrm{~mm}$ were filled at a porosity of 0.15 , and sufficient cycle steps were performed to satisfy the initial stress equilibrium [46]. Finally, when the EPS was generated, the rectangular wall was deleted, and the initial stress satisfied the requirement [47].

To track the VEP and vertical displacement above the CCT and the LEP on the side of the CCT, some measurement circles with a diameter of $6 \mathrm{~cm}$ were required for modeling. These measurement circles are usually taken to be 10 times the diameter of the soil particles. The detailed measurement circle location is shown in Figure 3.

2.3. Material Properties. In practice, the CCT is generally made of reinforced concrete or masonry, and the foundation is reinforced; therefore, their deformation is much smaller than the backfill. Hence, during modeling and analysis, the foundation and the CCT structure can be regarded as being rigid. Their tangent and normal stiffness were set to $10^{10} \mathrm{~N} /$ $\mathrm{m}$ in the simulation. The wall stiffness of the simulated slope was 10 times that of the stiffness of the soil particles. Additionally, the friction coefficient between the wall and the soil particles is taken as zero. This friction coefficient is consistent with the value recommended by Lai et al. [45] and Han and Bhandari [48].

In this study, the backfill material and the load reduction material were used. The backfill material was selected as loess with relative compactness of $R=85 \%$, cohesion of $c=31.11 \mathrm{kPa}$, and internal friction angle of $\phi=28.24^{\circ}$ [49]. The EPS, which is a load reduction material, was simulated by the disk particle unit of the linear contact model; its distribution range for a particle diameter from 6 to $10 \mathrm{~cm}$ and particle size follows the standard normal curve distribution.

Numerical biaxial tests and shear tests were typically carried out to evaluate the microscopic properties of geomaterials $[50,51]$. This study used the inverse modeling technique [48], whereby the micromechanical parameters were adjusted step by step in DEM simulations to approach the macromechanical properties of the test [52]. Thus, the micromechanical parameters of the numerical model were determined as presented in Table 2.

\section{Earth Pressure Analysis}

In the earth pressure analysis, the earth pressure variation was investigated, and the average earth pressure within the CCT range was calculated using the equivalent load method. The analysis results are based on (a) VEP and (b) LEP.

3.1. Vertical Earth Pressure Analysis. To investigate the variation of VEP above the CCT and average VEP in a range, which is immediately above the top of the CCT for cases S1 
TABLE 1: Scheme design.

\begin{tabular}{|c|c|c|c|c|c|c|c|}
\hline Scheme & $\begin{array}{l}\text { Filling height } \\
\text { (m) }\end{array}$ & $H / S$ ratio & $\begin{array}{l}\text { Load reduction } \\
\text { situation }\end{array}$ & $\begin{array}{l}\text { EPS width } \\
\text { (cm) }\end{array}$ & $\begin{array}{l}\text { EPS thickness } \\
(\mathrm{cm})\end{array}$ & $\begin{array}{c}\text { Groove width } \\
\text { ratio }\end{array}$ & Slope angle $\left({ }^{\circ}\right)$ \\
\hline S1 & 0 to 1.2 & 0.4 to 0.9 & $\mathrm{NO}$ & - & - & 3.0 & 70 \\
\hline $\mathrm{S} 2$ & 0 to 1.2 & 0.4 to 0.9 & YES & 30 & 15 & 3.0 & 70 \\
\hline
\end{tabular}

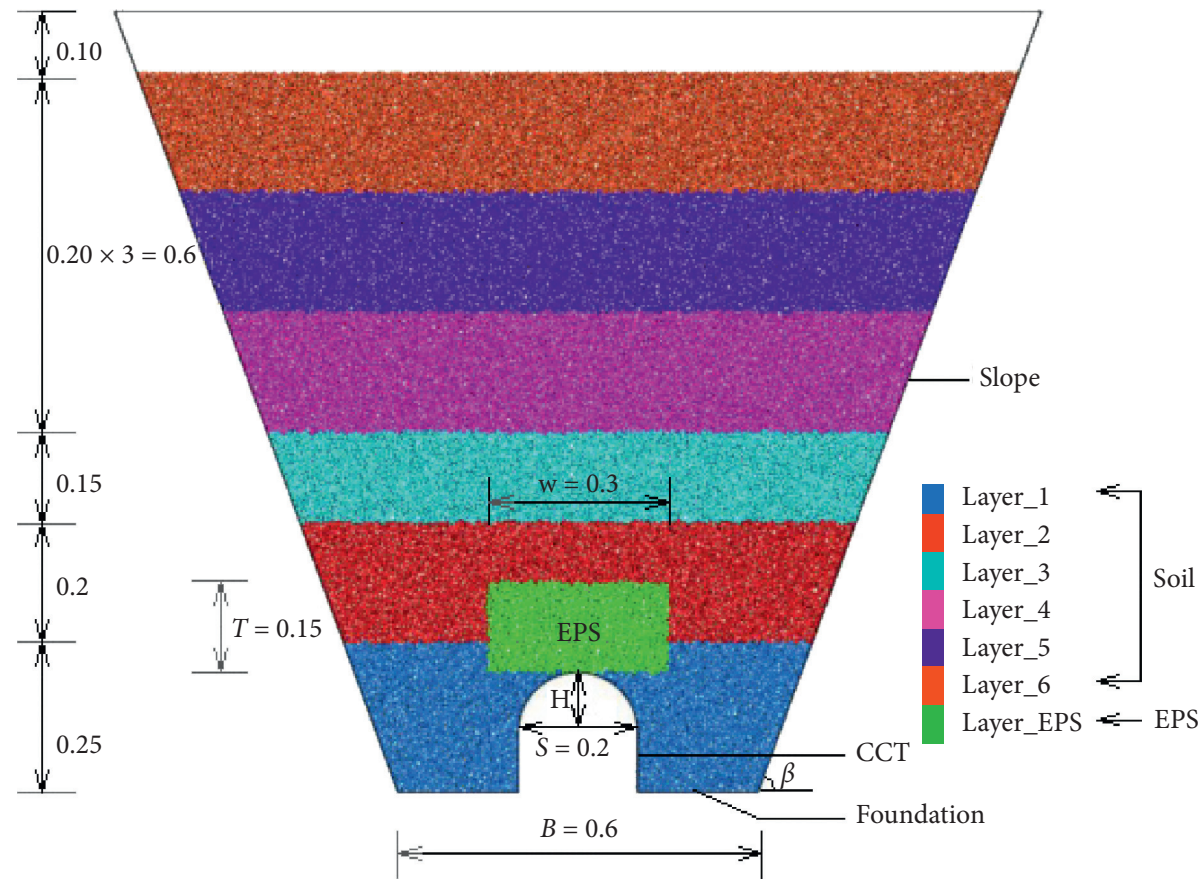

FIgURE 1: Schematic showing the discrete element model for a CCT (unit: $\mathrm{m}$ ).

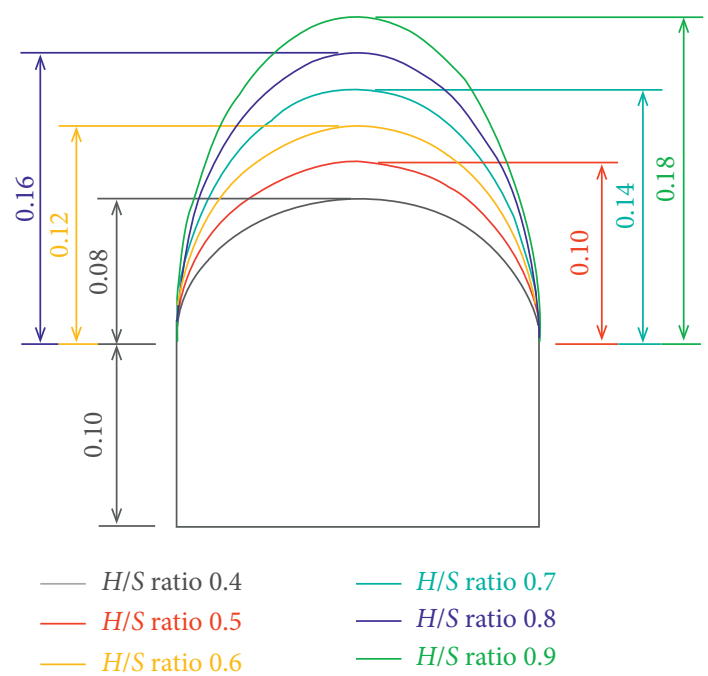

Figure 2: Variation of the $H / S$ ratio (unit: $\mathrm{m}$ ).

and S2, some measurement circles had to be created during modeling (see Figure 3). Amongst them, the VEP was tracked by 1 to 10 measurement circles. Simultaneously, the average VEP was tracked by 4 to 8 measurement circles. The analysis results are presented below.

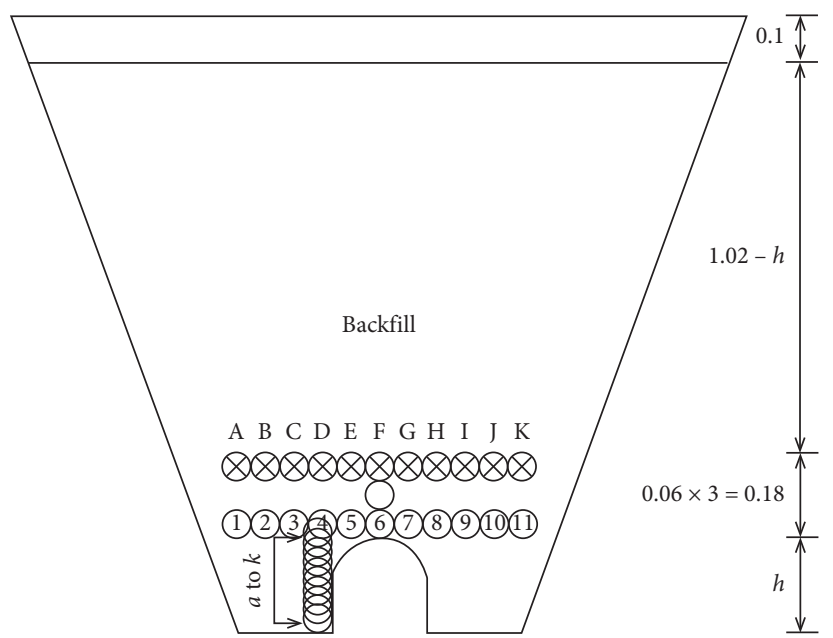

Stress measurement circle

$\times$ Displacement measurement circle

FIGURE 3: Arrangement of measuring points (unit: m).

3.1.1. Variation of Vertical Earth Pressure in Different Cases. Figure 4 shows the VEP curve variation for case S1 above the CCT when the $H / S$ ratios changed from 0.4 to 0.9 . The results revealed that the VEP was concentrated at the center and decreased symmetrically with increasing distance from the 
TABle 2: Micromechanical parameters of the numerical model.

\begin{tabular}{lccccccc}
\hline Parameter & Particle diameter $(\mathrm{mm})$ & $\begin{array}{c}\text { Density } \\
\left(\mathrm{kg} / \mathrm{m}^{3}\right)\end{array}$ & Normal stiffness $(\mathrm{N} / \mathrm{m})$ & $\begin{array}{c}\text { Shear stiffness } \\
(\mathrm{N} / \mathrm{m})\end{array}$ & $\begin{array}{c}\text { Friction } \\
\text { coefficient }\end{array}$ & $\begin{array}{c}\text { Normal bond } \\
\text { strength }(\mathrm{N})\end{array}$ & $\begin{array}{c}\text { Tangential bond } \\
\text { strength }(\mathrm{N})\end{array}$ \\
\hline Backfill & $6-10$ & 3600 & $5 e 7$ & $2 e 7$ & 0.8 & 600 & 600 \\
EPS & 1200 & $3 e 6$ & $2.5 e 6$ & 0.27 & - & - \\
\hline
\end{tabular}

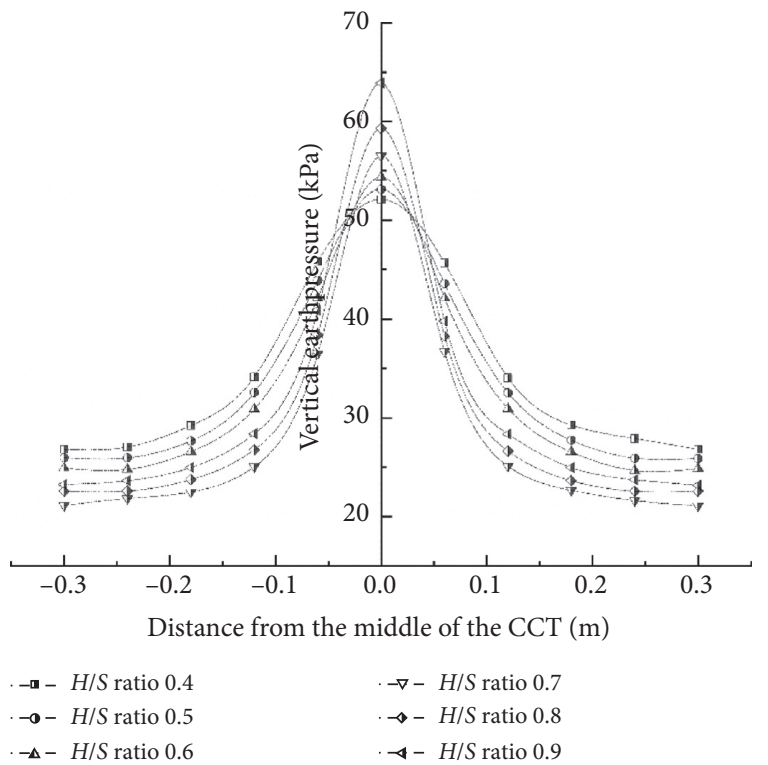

FIGURE 4: Variation of vertical eearth pressure for case $S 1$ on top of CCT.

center of the model (inversed V-shaped distribution), which means that the VEP curve variation is consistent with the laws proposed by $\mathrm{Li}$ et al. [41]. In a range of $5 \mathrm{~cm}(0.5 \mathrm{~S})$ from the center of the model, the VEP increased with the $H / S$ ratio because the vault shape of the CCT gradually became sharper, which resulted in the stress being concentrated above the CCT. Thus, the VEP significantly increased from $52.1 \mathrm{kPa}$ to $63.9 \mathrm{kPa}$ at the center of the model when the $H / S$ ratios changed from 0.4 to 0.9 . Beyond this range $(5$ to $30 \mathrm{~cm})$, the VEP sequentially increased according to the $H / S$ ratios of 0.7 , $0.8,0.9,0.6,0.5$, and 0.4. Moreover, the VEP distribution curve tended to be gentle, and the rate of change decreased.

Figure 5 shows the VEP curve variation for case S2 above the CCT when the $H / S$ ratios changed from 0.4 to 0.9 . When the EPS with a thickness of $15 \mathrm{~cm}$ and width of $30 \mathrm{~cm}$ (1.5S) was placed above the CCT, the VEP above the CCT was smaller than that on the side of the CCT (U-shaped distribution) and the maximum VEP value was located at a distance of $20 \mathrm{~cm}$ from the center of the model, owing to the load reduction effect of the EPS. Within the range of $10 \mathrm{~cm}$ (1.0S) from the center of the model, the VEP remained approximately unchanged (approximately $6.5 \mathrm{kPa}$ ) because the influence of the EPS load reduction on the earth pressure was the same and dominated, compared with the modified $H / S$. Beyond this range $(10$ to $30 \mathrm{~cm})$, the VEP change was relatively obvious.

Figure 6 compares the relationship between the VEP above the CCT and the $H / S$ ratio at points 1 and 6 (see

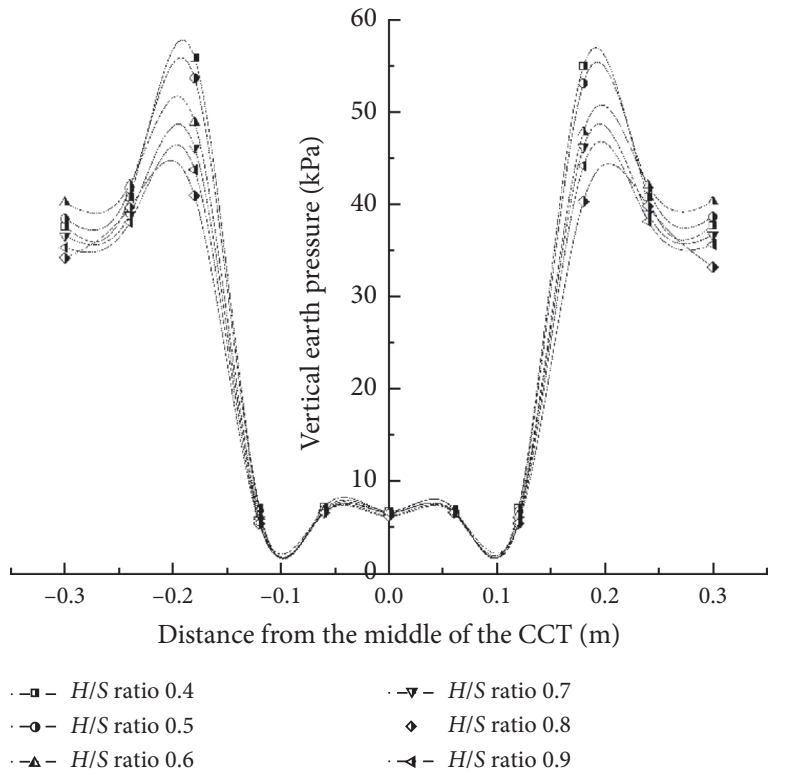

FIgURE 5: Variation of vertical eearth pressure for case S2 on top of CCT.

Figure 3) for cases S1 and S2. The research results revealed that the presence of EPS significantly reduced the overburden pressure above the CCT (point 6), but increased the VEP outside of the CCT (point 1). Without EPS, the VEP at point 6 gradually grew as the $H / S$ ratio increased; however, the VEP at point 1 reached a minimum value of $22.14 \mathrm{kPa}$ at the $H / S$ ratio of 0.7 , and the VEP change was relatively small compared with point 6 . With EPS, the VEP at point 1 was the smallest when the $H / S$ ratio was 0.8 , and its value was $34.18 \mathrm{kPa}$; however, the VEP at point 6 remained approximately unchanged. Thus, it can be seen that the $H / S$ ratio had a greater effect on the earth earth pressure at the top of the CCT when there was no load reduction for the EPS. In contrast, when the load was reduced above the top of the CCT, the effect on the earth earth pressure outside of the CCT was greater.

3.1.2. Variation of Average Vertical Earth Pressure in Different Cases. Figure 7 shows the comparison of the average VEP in cases $\mathrm{S} 1$ and $\mathrm{S} 2$, when the $H / S$ ratios changed from 0.4 to 0.9 . As shown in Figure 7(a), the average VEP for case $\mathrm{S} 1$ was distributed in a $\mathrm{V}$-shaped as the $H / S$ ratio increased. Within the $H / S$ ratio range from 0.4 to 0.7 , the average VEP rapidly decreased. However, the average VEP rapidly increased within the $H / S$ ratio range from 0.7 to 0.9 . The minimum value was $38.89 \mathrm{kPa}$ at the $H / S$ ratio of 0.7 . Thus, the $H / S$ ratio of 0.7 was considered as the optimal $H / S$ ratio 


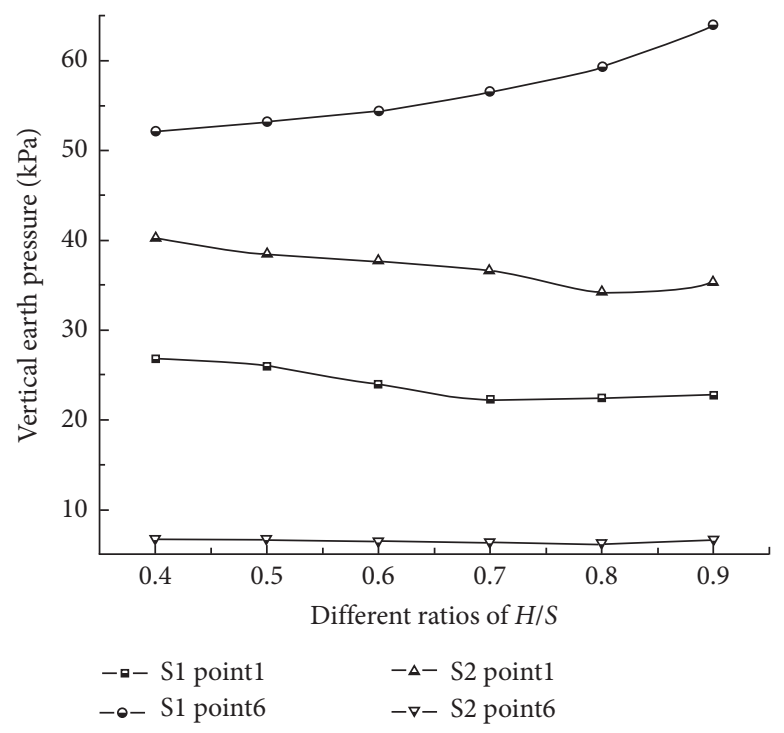

Figure 6: Vertical earth pressure of different $H / S$ ratios at points 1 and 6 for cases $S 1$ and S2.

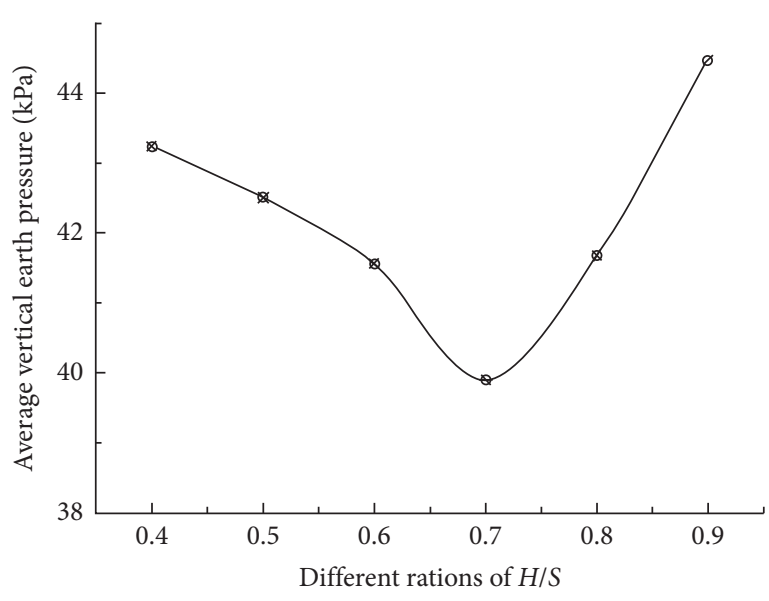

(a)

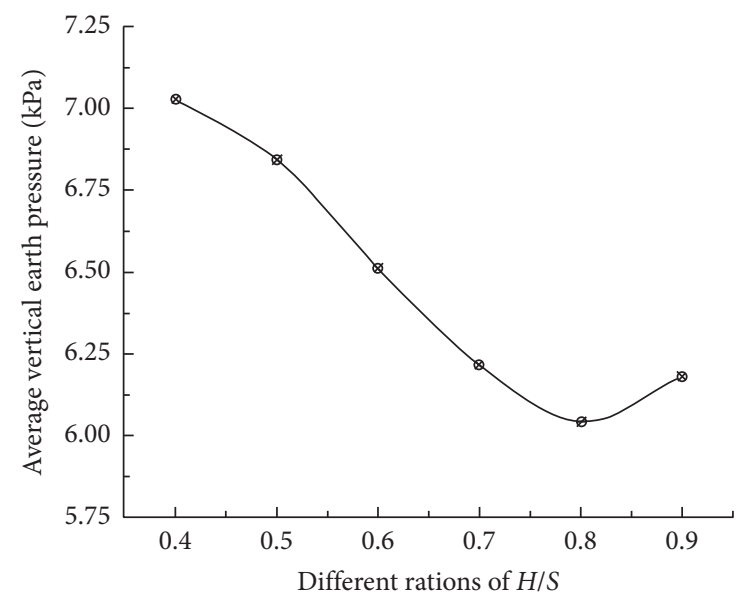

(b)

FIgURe 7: Average vertical earth pressure of different $H / S$ ratios within a range of CCT top for cases (a) S1 and (b) S2.

when there was no load reduction. Figure $7(\mathrm{~b})$ shows the variation of the average VEP with the change of the $H / S$ ratio for case S2. As can be seen, the average VEP first decreased and then increased, and reached the minimum value of $6.04 \mathrm{kPa}$ at the $H / S$ ratio of 0.8 . Therefore, the $H / S$ ratio of 0.8 was considered as the optimal $H / S$ ratio when a load reduction measure was applied.

3.2. Lateral Earth Pressure Analysis. To investigate the variation of LEP and average LEP on the side of the CCT for cases $\mathrm{S} 1$ and S2, some measurement circles, from a to $k$, had to be created during modeling (see Figure 3). The analysis results are presented below.

3.2.1. Variation of Lateral Earth Pressure in Different Cases. Figure 8 shows the LEP distribution on the side of the CCT for case S1. The LEP curve along the CCT height can be divided into three stages: stability (curve a), increase (curve b), and decrease (curve c). The minimum LEP value appeared at 0.4 times the height of the CCT. Additionally, the maximum LEP value appeared at 0.7 times the height of the CCT because the soil above the CCT slid along the curved arch under the action of VEP. Consequently, the lateral soil at the sides of the CCT was squeezed and offset some of the LEP. Within the range of curve a, the LEP magnitude remained approximately unchanged along with the CCT height, while the LEP gradually decreased as the $H / S$ ratio increased. Within the range of curve b, the LEP continuously increased along with the CCT height. Within the range of curve $c$, the LEP decreased along with the CCT height, and the LEP decreased as the $H / S$ ratio increased.

The LEP trend on the side of the CCT for case S2 (see Figure 9) is similar to the LEP trend for case S1 (see Figure 8). Differently, the maximum LEP value appeared at 0.9 times the height of the CCT and the LEP rapidly decreased as 


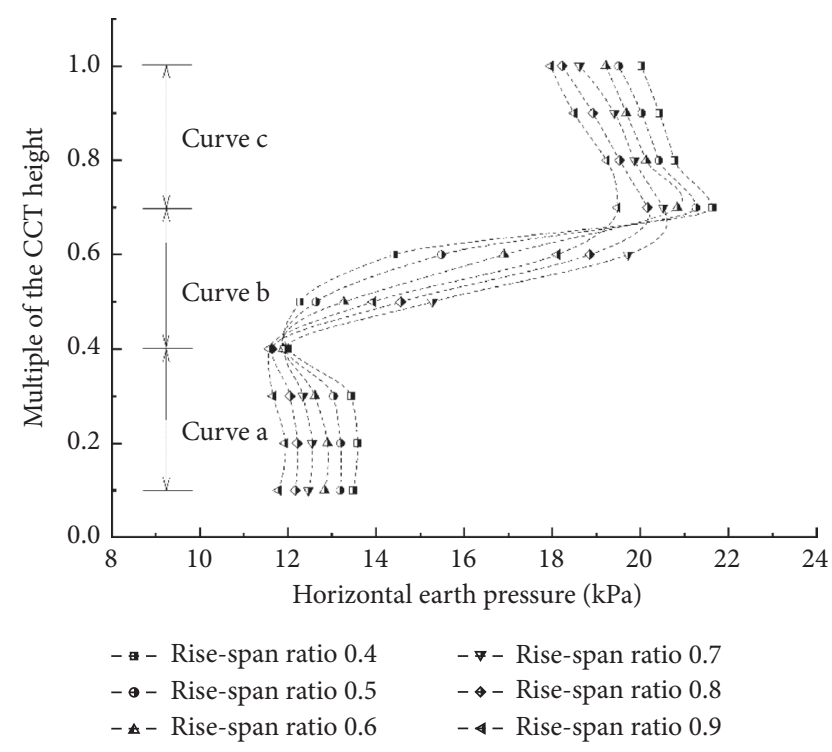

FIGURE 8: Variation of lateral earth pressure for case $S 1$ on the side of CCT.

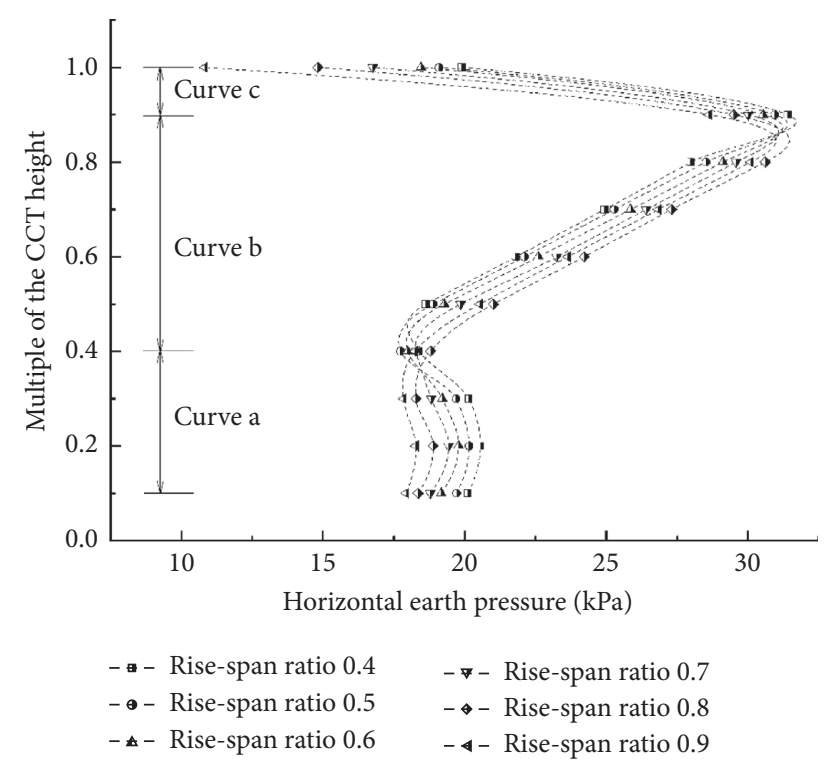

FIGURE 9: Variation of lateral earth pressure for case S2 on the side of CCT.

the $H / S$ ratio increased, owing to the EPS load reduction and sliding of soil on the top of the CCT within the range of curve c. Additionally, for case S2, the LEP magnitude on the side of the CCT was greater than that for case S1.

3.2.2. Variation of Average Lateral Earth Pressure in Different Cases. Figure 10 shows the average LEP of different $H / S$ ratios for cases $\mathrm{S} 1$ and $\mathrm{S} 2$. It can be seen that the average LEP increased when the $H / S$ ratio increased from 0.4 to 0.7 for case S1. The corresponding results changed from $15.78 \mathrm{kPa}$ to $16.41 \mathrm{kPa}$. However, when the $H / S$ ratio further increased to 0.9 , the average LEP did not continue to increase but rather began to decrease. The corresponding results decreased from $16.41 \mathrm{kPa}$ to $15.59 \mathrm{kPa}$. Therefore, the maximum value of the average LEP appeared at the $H / S$ ratio of 0.7. It can also be seen that the average LEP variation for case S2 was the same as that for case S1. The difference is that the magnitude of the average LEP was greater than that of case $\mathrm{S} 1$ and the maximum value, which occurred at the $H / S$ ratio of 0.8 , was $22.66 \mathrm{kPa}$.

By comparing and analyzing Figures 7 and 10, it can be seen that the average LEP on the side of the CCT was maximum, while the average VEP above the CCT was minimum.

\section{Vertical Displacement Analysis}

To investigate the vertical displacement variation and relative vertical displacement above the CCT for cases S1 and $\mathrm{S} 2$, the locations from A to $\mathrm{K}$ were used to track the vertical displacement of the soil particles above the CCT (see Figure 3). The analysis results are presented in Figure 11.

4.1. Variation of Vertical Displacement Nephograms for Soil Particles. The variation of the vertical displacement nephograms for the soil particles in different cases ((a) S1, H/ $S=0.4$, (b) S1, $H / S=0.9$, (c) S2, $H / S=0.4$, (d) S2, $H / S=0.9$ ) are shown in Figure 12. By comparing Figures 12(a) and 12(c) or Figures 12(b) and 12(d), the soil particles displacement on the side of the CCT was greater than that above the CCT for case S1, while the load reduction method could modify the vertical displacement of the soil particles, for which the maximum displacement appeared in the middle. By comparing Figures 12(a) and 12(b) or Figures 12(c) and $12(\mathrm{~d})$, when the $H / S$ ratio increased, the soil particle displacement changed more drastically at the same backfill height.

4.2. Relative Vertical Displacement and Height of Equal Settlement Plane. In this study, the relative vertical displacement was considered as the displacement difference between points 4 and 6 . The horizontal plane was considered as the displacement of the equal settlement plane when the relative vertical displacement was less than $0.001 \mathrm{~mm}$. The vertical distance of the equal settlement plane from the center of the model was considered as the height of the equal settlement plane.

When there was no load reduction, the relative vertical displacement caused by the different settlement of the internal and external soil column resulted in a downward frictional force, which increased the VEP within the CCT range. Thus, the VEP within the CCT range decreased with the relative vertical displacement. When there was EPS load reduction, the settlement of the external soil column was smaller than the settlement of the internal soil column, which resulted in an upward frictional force that decreased the VEP within the CCT range. Thus, the VEP within the CCT range decreased with the increase of relative vertical displacement. Additionally, the frictional force was related to the frictional contact length of the internal and external soil columns. With a shorter frictional length, the frictional 


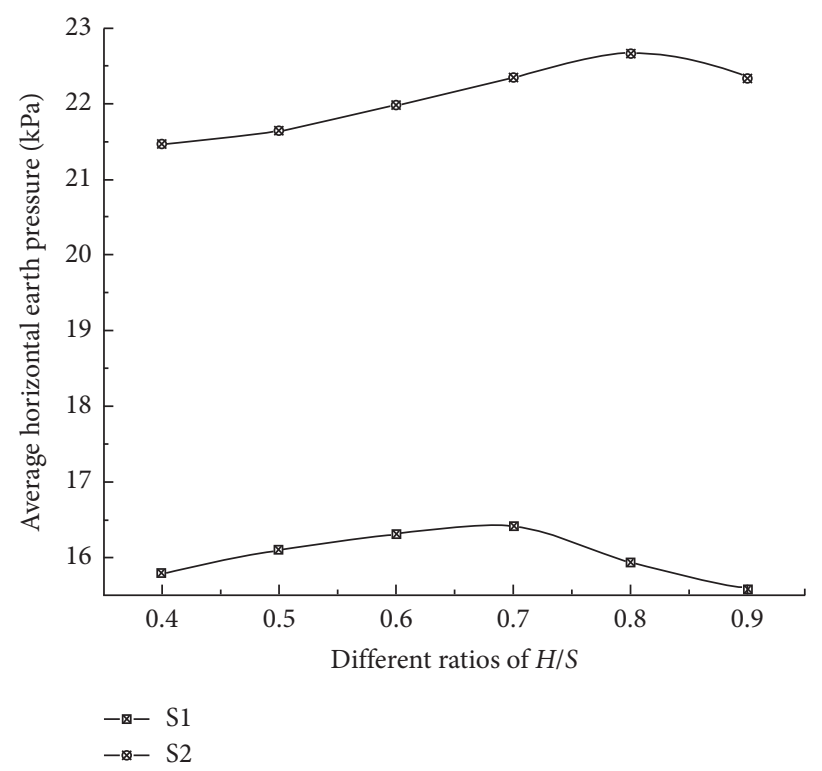

FIgURE 10: Average lateral earth pressure of different $H / S$ ratios within the range of CCT side for cases S1 and S2.

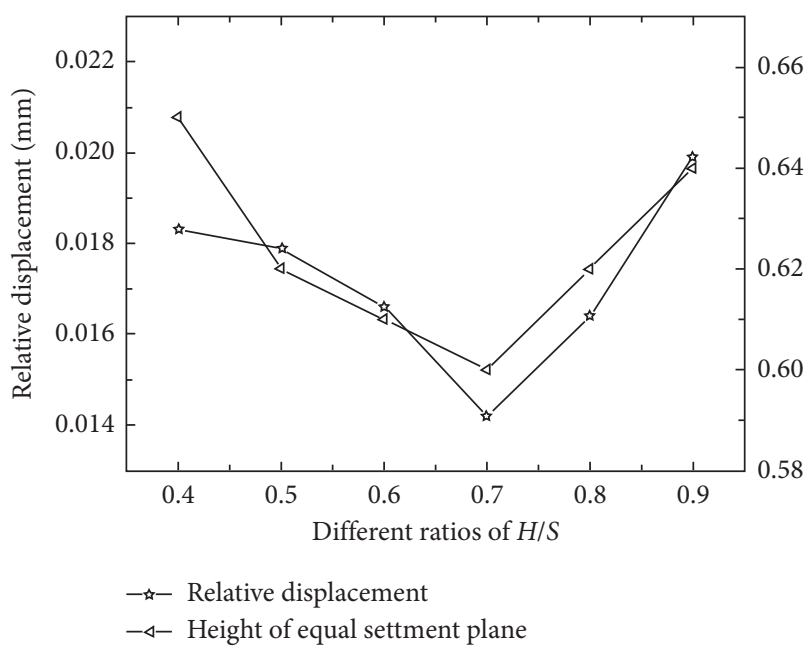

(a)

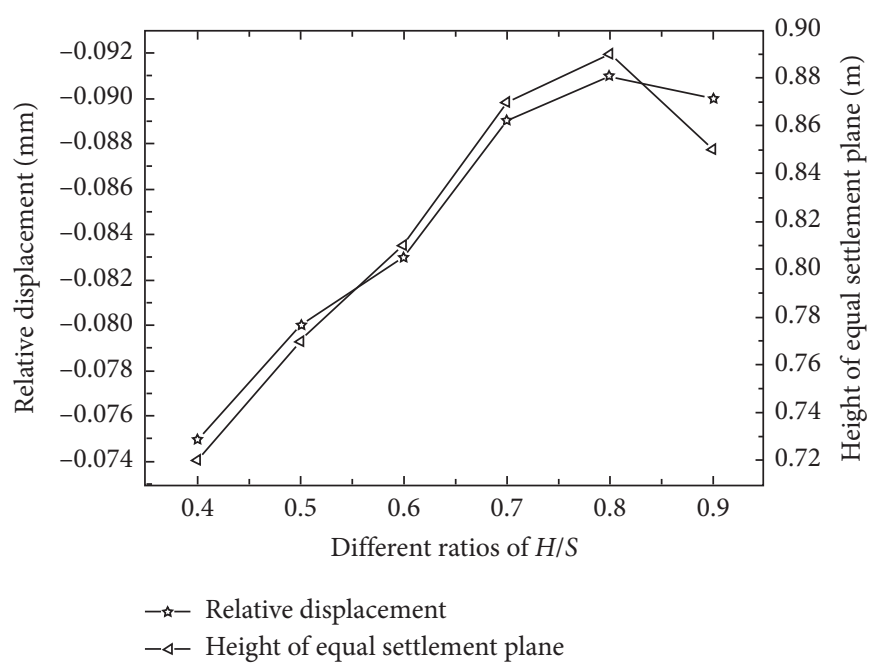

(b)

FIGURE 11: Variations of relative displacement and height of equal settlement plane on top of CCT for cases (a) S1 and (b) S2.

force became smaller, which resulted in a shorter distance between the equal settlement plane and the center of the model. These theoretical analyses are confirmed by Figures 11(a) and 11(b).

Figure 11(a) shows the relative vertical displacement and height of equal settlement plane variations with the change of the $H / S$ ratio for case $S 1$. The relative vertical displacement variation was approximately the same as that of the height of an equal settlement plane, which first decreased and then increased; the minimum value appeared at the $H / S$ ratio of 0.7. The relative vertical displacement decreased from $0.018 \mathrm{~mm}$ to $0.014 \mathrm{~mm}$ when the $H / S$ ratios changed from 0.4 to 0.7 . The relative vertical displacement increased to $0.020 \mathrm{~mm}$ when the $H / S$ ratios exceeded the range of 0.7 to
0.9. Similarly, the height of the equal settlement plane decreased from $0.65 \mathrm{~m}$ to $0.60 \mathrm{~m}$ when the $H / S$ ratios changed from 0.4 to 0.7 and then increased from $0.60 \mathrm{~m}$ to $0.64 \mathrm{~m}$ when the $H / S$ ratios changed from 0.7 to 0.9 . Figure $11(\mathrm{~b})$ shows the relative vertical displacement of the soil particles and the height of equal settlement plane variations with the change of the $H / S$ ratio for case S2. The relative vertical displacement and height of equal settlement plane variations first increased and then decreased, and the maximum value appeared at the $H / S$ ratio of 0.8. As shown in Figure 11, the results for the relative vertical displacement and height of equal settlement planes were the same as the results of the above-mentioned theoretical analysis. When there was no load reduction, the relative vertical displacement and height 


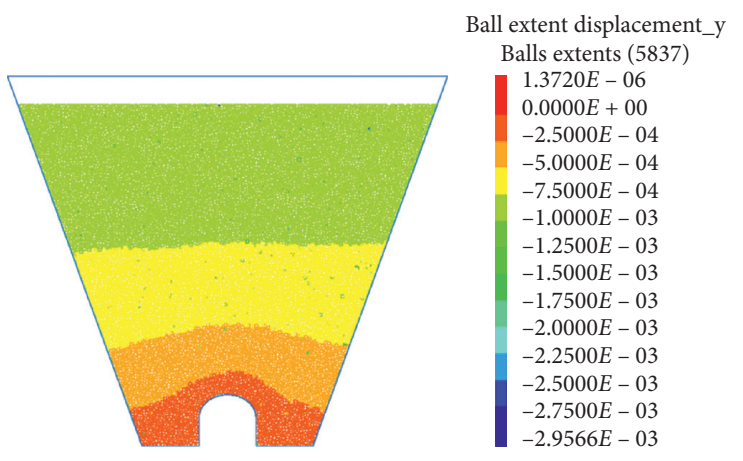

(a)

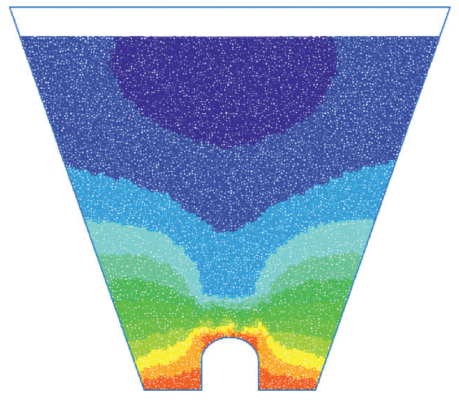

(c)

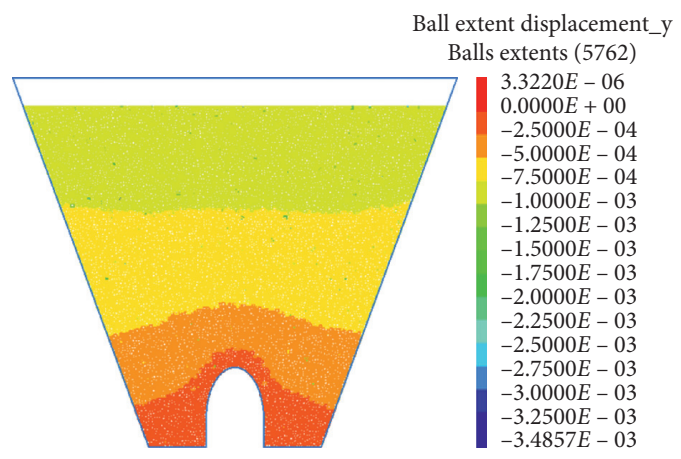

(b)

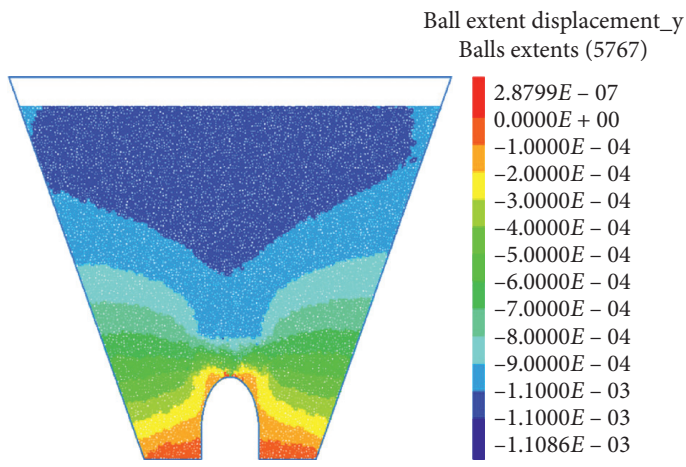

(d)

FIGURE 12: Variation of vertical displacement nephograms of soil particles for cases (a) $\mathrm{S} 1, H / S=0.4$; (b) $\mathrm{S} 1, H / S=0.9$; (c) $\mathrm{S} 2, H / S=0.4$; (d) S2, $H / S=0.9$.

of the equal settlement plane decreased with the average VEP. When there was EPS load reduction, the relative vertical displacement and the height of the equal settlement plane increased with the decrease of the average VEP.

\section{Microscopic Analysis of Soil Particles}

To further investigate the load distribution and transfer mechanism of CCT, it was necessary to analyze factors, such as the porosity, coordination number, and contact force chain, at the microscopic level. Notably, the porosity is the ratio of the pore area to the entire model area. The coordination number, which is an important index for evaluating whether a granular system has great contact and compactness, refers to the average contact number of the soil particles in the model. The contact force chain was used to embody how the load was transmitted in the soil.

5.1. Porosity and Coordination Number. The porosity and coordination number variations are depicted in Figure 13. As shown in Figure 13(a), the porosity first increased and then decreased, and the coordination number variation was exactly contrary to the porosity in case S1. The maximum value of the coordination number and minimum value of porosity simultaneously appeared when the $H / S$ ratio was 0.7. Similarly, the porosity variation and coordination number for case S2 was the same as that for case S1, with the exception of the maximum porosity value and minimum coordination number value, which simultaneously appeared at the position where the $H / S$ ratio was 0.8 (see Figure 13(b)). Thus, it was concluded that the minimum coordination number and maximum porosity appeared simultaneously. Additionally, this trend is consistent with the optimal $H / S$ ratio, which had a smaller VEP. In other words, the applied earth earth pressure was minimum, and this led to the increase of porosity and decrease of the coordination number.

5.2. Contact Force Chain. The contact force chain changes for four cases: (a) $\mathrm{S} 1, H / S=0.4$; (b) $\mathrm{S} 1, H / S=0.9$; (c) $\mathrm{S} 2, H$ / $S=0.4$; (d) S2, $H / S=0.9$ are depicted in Figure 14. The black and red lines represent the compressive and tensile forces, respectively. The magnitude of the force chains is represented by the density of these lines. Figures 14(a) and 14(b) show the contact force distributions for the $H / S$ ratios of 0.4 and 0.9 in case $S 1$, respectively. When the $H / S$ ratio increased, the contact force chains gradually concentrated toward the top of the CCT, and the earth earth pressure at the center of the model correspondingly increased. Simultaneously, the contact force chains on both sides of the CCT area gradually became sparse. This change is consistent with the results presented in Figure 6 for which the change of the $H / S$ ratio had a greater effect on the earth earth pressure above the CCT without the EPS load reduction. Figures 14(c) and 14(d) show the contact force chain distributions for the $H / S$ ratios of 0.4 and 0.9 in case S2, respectively. As can be 


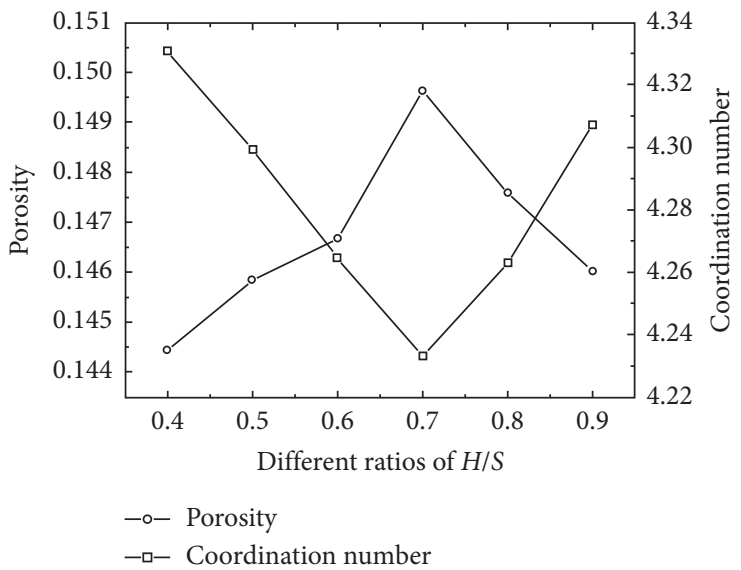

(a)

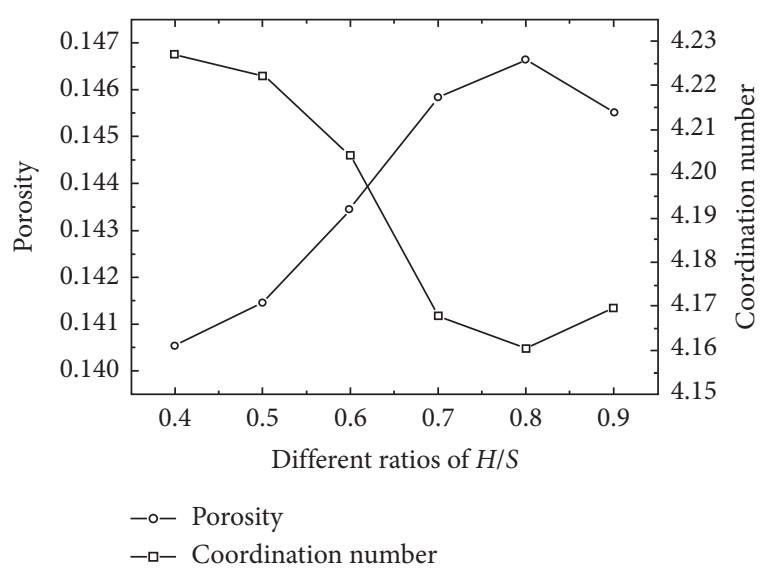

(b)

FIGURE 13: Variations of porosity and coordination number on top of CCT for cases (a) S1 and (b) S2.

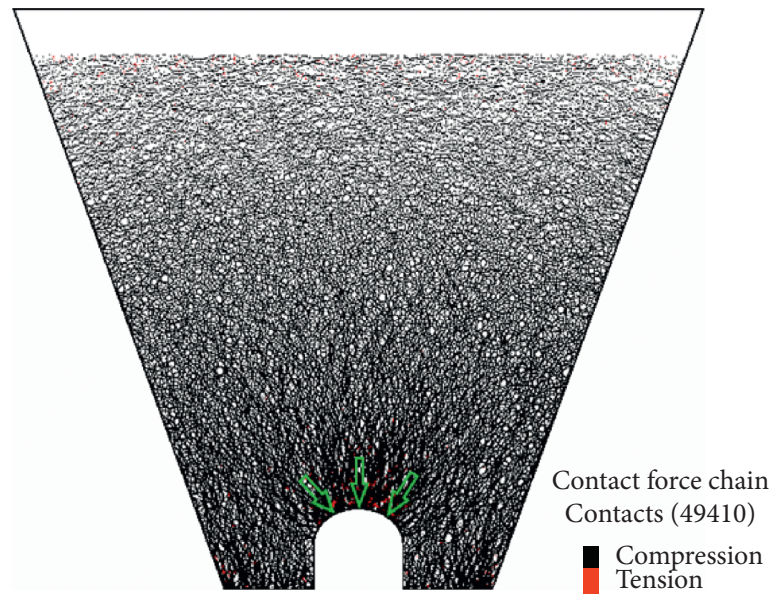

(a)

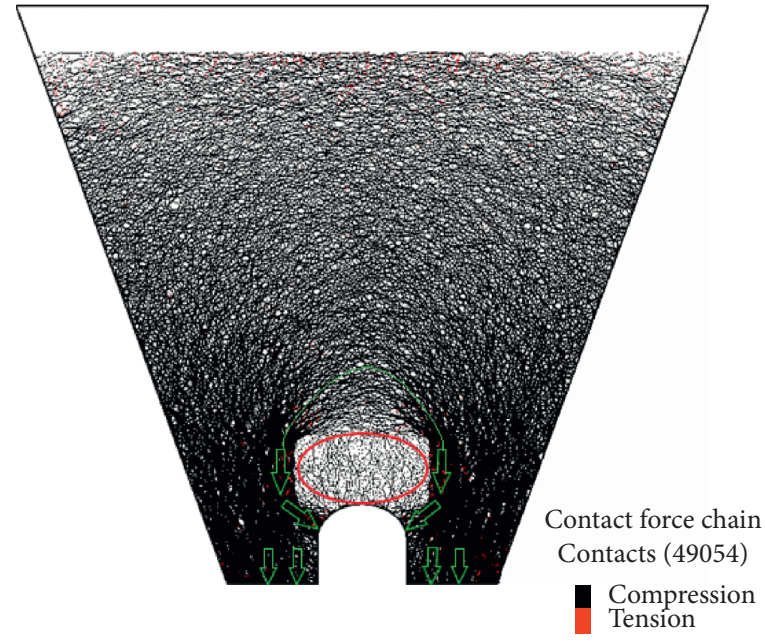

(c)

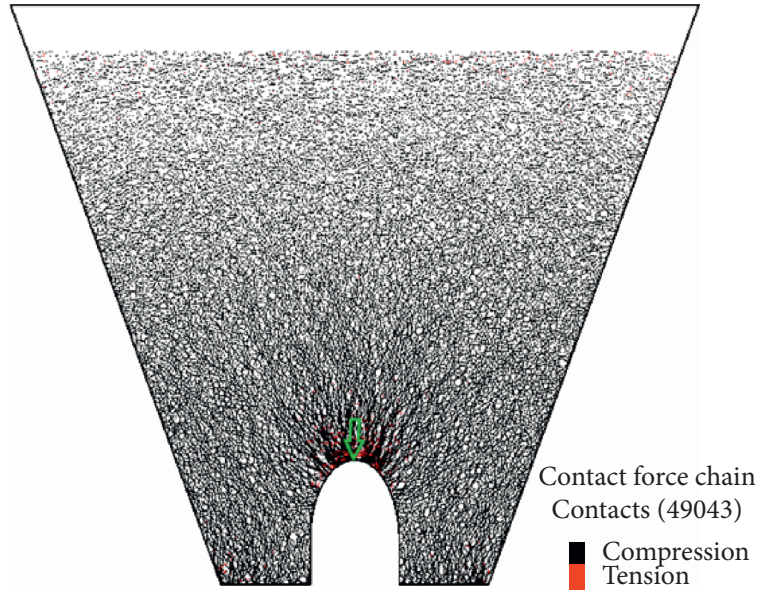

(b)

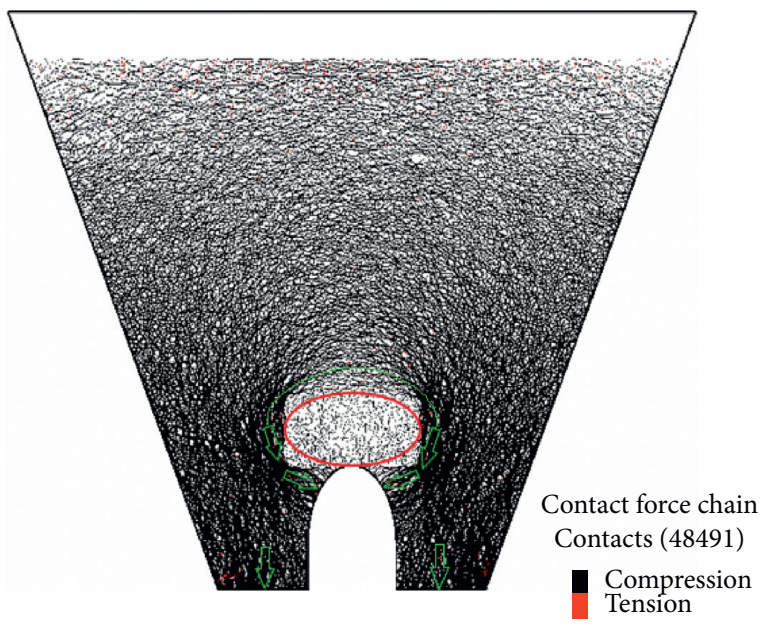

(d)

Figure 14: Contact force chain for cases (a) $S 1, H / S=0.4$; (b) $S 1, H / S=0.9$; (c) $S 2, H / S=0.4$; (d) $S 2, H / S=0.9$. 
seen, the load reduction results that are oval zones with sparse contact force chains were essentially the same, and the contact force chains were sparse on both sides of the CCT with the increase of the $H / S$ ratio. This change is consistent with the results shown in Figure 6(b), for which the change of the $H / S$ ratio had a greater effect on the earth earth pressure outside of the CCT with the EPS load reduction. By comparing Figures 14(a) and 14(c) or Figures 14(b) and 14(d), it can be seen that the contact force chain with the EPS load reduction was transferred from the top of the CCT to both sides of the CCT, which is consistent with the VEP variations shown in Figures 4 and 5.

\section{Discussion}

According to the results of the PFC2D simulation, the earth earth pressure magnitude was different with a different shape of the CCT lining structure (referred to as the $H / S$ ratio in this paper). Therefore, the CCT structure was optimized by modifying the $H / S$ ratio to reduce the earth earth pressure of the CCT. Moreover, by coupling the EPS load reduction and modification of the $H / S$ ratio, the VEP of the CCT changed from an inversed $\mathrm{V}$-shaped distribution to a $\mathrm{U}$-shaped distribution, and the VEP of the CCT was greatly reduced. In short, the combined effect of load reduction and modification of the $H / S$ ratio was more useful for reducing the earth earth pressure and improving the safety of the structure when subjected to extrahigh backfill.

This study investigated the earth earth pressure distribution and vertical displacement around the CCT when using loess as a high backfill material. The impact of other backfilling materials on the earth earth pressure was not considered, and the long-term stability of the earth earth pressure was ignored. In the modeling process, the CCT and foundation were considered as rigid bodies. Therefore, the deformation of the CCT and the foundation were not considered. Additionally, other influencing factors, such as the size and position of the EPS, groove width ratio, and slope angle, were not investigated in this study. However, the effect of the $H / S$ ratio and the coupling effect of the EPS and $H / S$ ratio on the earth pressure could be clearly identified for the HFCCT.

\section{Conclusion}

PFC2D software was used to investigate the VEP and LEP distributions and relative vertical displacements for HFCCTs with different $H / S$ ratios, regardless of whether EPS was used. Moreover, the earth pressure of the HFCCTs was analyzed according to three microlevels: porosity, coordination number, and contact force chain. Several conclusions were drawn from this study, as follows:

(1) The earth pressure distribution was optimized by changing the $H / S$ ratio of the CCT. When the $H / S$ ratio increased, the average VEP, relative vertical displacement, and height of equal settlement plane first decreased and then increased, while the average
LEP first increased and then decreased. The turning points appeared at the $H / S$ ratio of 0.7. Therefore, in terms of changing the $H / S$ ratio, the most beneficial vault for the CCT structure was determined as $H$ / $S=0.7$.

(2) The coupled effect of the EPS load reduction and modified CCT $H / S$ ratio significantly changed the earth pressure distribution, which transferred the load from the top to the sides of the CCT and slopes. Moreover, when the $H / S$ ratio increased, the average VEP first decreased and then increased, while the average LEP, relative vertical displacement, and height of equal settlement plane first increased and then decreased. Therefore, in terms of the coupling effect of EPS load reduction and $H / S$ ratio modification, an optimal $H / S$ ratio of 0.8 is recommended.

(3) The macromechanical performances were influenced by the particles' micromechanical properties. The computational results of the micromechanical properties, such as the porosity, coordination number, and contact force chain, are consistent with the earth pressure around the CCT. In other words, the minimum earth pressure occurred when the coordination number was minimum and the porosity was maximum.

\section{Data Availability}

The data used in this work are available from the corresponding author upon request.

\section{Conflicts of Interest}

There are no conflicts of interest regarding this submission.

\section{Acknowledgments}

This study was supported by the National Science Foundation of China (51668036 and 51868041), General Projects of Scientific Research of High Education in Gansu (2017A111), the Changjiang Scholars Program and Innovative Research Team in the University (IRT_15R29), and the Energy Geomechanics Laboratory at the University of North Dakota, USA.

\section{References}

[1] A. Marston, Second Progress Report to the Joint Concrete Culvert Pipe Committee, Iowa Engineering Experimental Station, Ames, IA, USA, 1922.

[2] A. N. Dancygier and D. Z. Yankelevsky, "A soft layer to control soil arching above a buried structure," Engineering Structures, vol. 18, no. 5, pp. 378-386, 1996.

[3] N. G. Larsen and J. G. Hendrickson, "A practical method for constructing rigid conduits under high fills," in Proceedings of the 41st Annual Meeting of the Highway Research Board, vol. 41, pp. 273-280, Highway Research Board, Washington, DC, USA, January 1962. 
[4] B. Bai, "The measure for reducing the vertical earth pressure on the buried rigid structure," Rock and Soil Mechanics, vol. 18, no. 1, pp. 35-39, 1997, in Chinese.

[5] E. M. Palmeira and H. K. P. A. Andrade, "Protection of buried pipes against accidental damage using geosynthetics," Geosynthetics International, vol. 17, no. 4, pp. 228-241, 2010.

[6] G. T. Mehrjardi, S. N. Moghaddas Tafreshi, and A. R. Dawson, "Pipe response in a geocell-reinforced trench and compaction considerations," Geosynthetics International, vol. 20, no. 2, pp. 105-118, 2013.

[7] P. Villard, A. Huckert, and L. Briançon, "Load transfer mechanisms in geotextile-reinforced embankments overlying voids: numerical approach and design," Geotextiles and Geomembranes, vol. 44, no. 3, pp. 381-395, 2016.

[8] H. J. Lee and H. S. Roh, "The use of recycled tire chips to minimize dynamic earth pressure during compaction of backfill," Construction and Building Materials, vol. 21, no. 5, pp. 1016-1026, 2007.

[9] J. Vaslestad, T. H. Johansen, and W. Holm, "Load reduction on rigid culverts beneath high fills: long-term behavior," Transporation Research Board, vol. 1415, pp. 58-68, 1993.

[10] M. G. Spangler, "A practical application of the imperfect ditch method of construction," in Proceedings of the Thirty-eventh Annual Meeting of the Highway Research Board, vol. 37, pp. 271-277, Highway Research Board, Washington, DC, USA, January 1958.

[11] R. K. Taylor, "Induced trench method of culvert installation," Highway Research Record No. 52, vol. 52, pp. 15-31, Highway Research Board, Washington, DC, USA, 1973.

[12] R. P. McAffee and A. J. Valsangkar, "Geotechnical properties of compressible materials used for induced trench construction," Journal of Testing and Evaluation, vol. 32, no. 2, pp. 143-152, 2004.

[13] J. Vaslestad, "Soil structure interaction of buried culverts," Ph.D. thesis, Norwegian Institute of Technology, Trondheim, Norway, 1990.

[14] W. Zhang, B. Liu, and Y. Xie, "Field test and numerical simulation study on the load reducing effect of EPS on the highly filled culvert," Journal Highway Transportation Research. Development China, vol. 23, no. 12, pp. 54-57, 2006, in Chinese.

[15] M. A. Meguid, M. G. Hussein, M. R. Ahmed, Z. Omeman, and J. Whalen, "Investigation of soil-geosynthetic-structure interaction associated with induced trench installation," Geotextiles and Geomembranes, vol. 45, no. 4, pp. 320-330, 2017.

[16] J. J. Zheng, Q. Ma, and J. Zhang, “Calculation of vertical earth pressure on load reduction culverts under embankments by reinforcement," Chinese Journal of Geotechnical Engineering, vol. 33, no. 7, pp. 1135-1141, 2011, in Chinese.

[17] M. Ahmed, V. Tran, and M. A. Meguid, "On the role of geogrid reinforcement in reducing earth pressures on buried pipes: experimental and numerical investigations," Soils and Foundations, vol. 55, no. 3, pp. 588-599, 2015.

[18] H. El Naggar, A. Turan, and A. Valsangkar, "Earth pressure reduction system using geogrid-reinforced platform bridging for buried utilities," Journal of Geotechnical and Geoenvironmental Engineering, vol. 141, no. 6, pp. 15-24, 2015.

[19] A. Dasgupta and B. Sengupta, "Large-scale model test on square box culvert backfilled with sand," Journal of Geotechnical Engineering, vol. 117, no. 1, pp. 156-161, 1991.

[20] M. Z. Yang, "Evaluation of factors affecting earth pressures on buried box culverts," Ph.D. thesis, University of Tennessee, Knoxville, TN, USA, 2000.
[21] K. Kim and C. H. Yoo, "Design loading on deeply buried box culverts," Journal of Geotechnical and Geoenvironmental Engineering, vol. 131, no. 1, pp. 20-27, 2005.

[22] B. L. McGuigan and A. J. Valsangkar, "Centrifuge testing and numerical analysis of box culverts installed in induced trenches," Canadian Geotechnical Journal, vol. 47, no. 2, pp. 147-163, 2010.

[23] B. L. McGuigan and A. J. Valsangkar, "Earth pressures on twin positive projecting and induced trench box culverts under high embankments," Canadian Geotechnical Journal, vol. 48, no. 2, pp. 173-185, 2011.

[24] O. S. Oshati, A. J. Valsangkar, and A. B. Schriver, "Earth pressures exerted on an induced trench cast-in-place doublecell rectangular box culvert," Canadian Geotechnical Journal, vol. 49, no. 11, pp. 1267-1284, 2012.

[25] B. Chen and L. Sun, "Performance of a reinforced concrete box culvert installed in trapezoidal trenches," Journal of Bridge Engineering, vol. 19, no. 1, pp. 120-130, 2014.

[26] G. Masoud, A. Ali, and M. Maziar, "Shear strength of top slab of reinforced concrete box culverts," ACI Structural Journal, vol. 116, no. 6, 2019.

[27] R. M. Bennett, S. M. Wood, E. C. Drumm, and N. R. Rainwater, "Vertical loads on concrete box culverts under high embankments," Journal of Bridge Engineering, vol. 10, no. 6, pp. 643-649, 2005.

[28] F. X. Zhang, "Internal force analysis and type selection of arch culverts," Journal of Hehai University, vol. 3, pp. 58-63, 1995, in Chinese.

[29] M. G. Spangler, "Underground conduits-an appraisal of modern research," Transportation American Society of Civil Engineers, vol. 113, no. 1, pp. 316-345, 1948.

[30] M. G. Spangler, "A theory of loads on negative projecting conduits," in Proceedings of the thirtieth Annual Meeting of the Highway Research Board, Highway Research Board, vol. 30, pp. 153-161, Highway Research Board, Washington, DC, USA, January 1950.

[31] M. G. Spangler, Field Measurements of the Settlement Ratios of Various Highway Culverts, Iowa Engineering Experiment Station, Ames, IA, USA, 1950.

[32] N. S. D. Liedberg, "Load reduction on a rigid pipe: pilot study of a soft cushion installation," Transportation Research Record: Journal of the Transportation Research Board, vol. 1594, no. 1, pp. 217-223, 1997.

[33] R. P. McAffee and A. J. Valsangkar, "Field performance, centrifuge testing, and numerical modelling of an induced trench installation," Canadian Geotechnical Journal, vol. 45, no. 1, pp. 85-101, 2008.

[34] B. L. McGuigan and A. J. Valsangkar, "Field monitoring and analysis of twin $3660 \mathrm{~mm}$ inside diameter induced trench culverts installed under $21.7 \mathrm{~m}$ of fill," Canadian Geotechnical Journal, vol. 48, no. 5, pp. 781-794, 2011.

[35] X. W. Yang and Y. X. Zhang, "Study on arch action and earth pressure theory for culverts under high embankment," Journal of Rock Mechanics and Engineering, vol. 24, no. 21, pp. 3887-3893, 2005, in Chinese.

[36] J. J. Zheng, B. G. Chen, and S. B. Zhang, "Experimental investigation and numerical simulation of nonlinear earth pressure or trench-buried culverts," Chinese Journal of Geotechnical Engineering, vol. 30, no. 12, pp. 1771-1777, 2008, in Chinese.

[37] X. L. Wang, A. L. Zhang, T. Li, and S. S. Zhou, "Numerical simulation of covered culverts water surface profile at Jinan section in south-to-north water transfer project," in Proceedings 
of the 5th International Conference on Bioinformatics and Biomedical Engineering, (iCBBE), Wuhan, China, May 2011.

[38] C. Machelski and G. Antoniszyn, "Load rate of the circumferential sector of soil-steel bridge structures," Archives of Civil and Mechanical Engineering, vol. 5, no. 4, pp. 85-102, 2005.

[39] H. Vladimir, E. Jan, and M. Lumir, "Shape optimization of concrete buried arches," Engineering Structures, vol. 48, pp. 716-726, 2013.

[40] T. Y. Xu, M. N. Wang, L. Yu, Y. C. Dong, and Y. Tian, "Research on the earth pressure and internal force of a highfill open-cut tunnel using a bilayer lining design: a field test using an FBG automatic data acquisition system," Sensors, vol. 19, no. 7, p. 1487, 2019.

[41] S. Li, I. H. Ho, L. Ma, Y. X. Yao, and C. D. Wang, "Load reduction on high-filled cut-and-cover tunnel using discrete element method," Computer and Geotechnics, vol. 114, p. 103149, 2019.

[42] S. Li, Y. X. Yao, I. H. Ho, L. Ma, and C. D. Wang, "Coupled effect of expanded polystyrene and geogrid on load reduction for high-filled cut-and-cover tunnels using the discrete element method," International Journal of Geomechanics, vol. 20, no. 6, p. 04020052, 2020.

[43] S. Li, G. Q. Han, I. H. Ho, L. Ma, Q. Wang, and B. Yu, "Coupled effect of cross-sectional shape and load reduction on high-filled cut-and-cover tunnels considering soilstructure interaction," International Journal of Geomechanics, vol. 20, no. 7, 2020.

[44] P. A. Cundall and O. D. L. Strack, "A discrete numerical model for granular assemblies," Géotechnique, vol. 29, no. 1, pp. 47-65, 1979.

[45] H.-J. Lai, J.-J. Zheng, J. Zhang, R.-J. Zhang, and L. Cui, "DEM analysis of "soil"-arching within geogrid-reinforced and unreinforced pile-supported embankments," Computers and Geotechnics, vol. 61, pp. 13-23, 2014.

[46] A. Bhandari and J. Han, "Investigation of geotextile-soil interaction under a cyclic vertical load using the discrete element method," Geotextiles and Geomembranes, vol. 28, no. 1, pp. 33-43, 2010.

[47] J. Han, A. Bhandari, and F. Wang, "DEM analysis of stresses and deformations of geogrid-reinforced embankments over piles," International Journal of Geomechanics, vol. 12, no. 4, pp. 340-350, 2012.

[48] J. Han and A. Bhandari, "Evaluation of geogrid-reinforced pile-supported embankments under cyclic loading using discrete element method," in Advances in Ground Improvement, pp. 73-82, ASCE, Reston, VA, USA, 2009.

[49] S. Li, L. Ma, Q. C. Wang, S. Z. Li, J. X. Li, and Y. J. Zhang, "Model tests and numerical simulations of earth pressure for unloading structures of high fill open cut tunnel," Chinese Journal of Geotechnical Engineering, vol. 38, no. 4, pp. 636642, 2016, in Chinese.

[50] B. Chareyre and P. Villard, "Discrete element modeling of curved geosynthetic anchorages with known macro-properties," in The Numerical Modeling in Micromechanics via Particle Methods, Taylor and Francis Group, Milton Park, UK, 2002.

[51] L. Zhang and C. Thornton, "A numerical examination of the direct shear test," Géotechnique, vol. 57, no. 4, pp. 343-354, 2007.

[52] R. Rui, F. van Tol, X.-L. Xia, S. van Eekelen, G. Hu, and Y.-y. Xia, "Evolution of soil arching; 2D DEM simulations," Computers and Geotechnics, vol. 73, no. 3, pp. 199-209, 2016. 